\title{
Responses of Overwintering Halyomorpha halys (Hemiptera: Pentatomidae) to Dead Conspecifics
}

\author{
Benjamin D. Chambers, ${ }^{1,4, \odot}$ Tracy C. Leskey, ${ }^{2}$ Annie R. Pearce, ${ }^{1}$ and Thomas P. Kuhar ${ }^{3, \bullet}$
}

'Department of Building Construction, Virginia Tech, Bishop Favrao Hall, Room 330A, 1345 Perry Street, Blacksburg, VA 24061, ${ }^{2}$ US Department of Agriculture, Appalachian Fruit Research Station, 2217 Wiltshire Road, Kearneysville, WV 25430, ${ }^{3}$ Department of Entomology, Virginia Tech, Price Hall, Room 216A, 170 Drillfield Drive, Blacksburg, VA 24061, and ${ }^{4}$ Corresponding author, e-mail: bdc0112@vt.edu

Subject Editor: John Trumble

Received 22 September 2018; Editorial decision 7 January 2019

\begin{abstract}
Overwintering brown marmorated stink bugs (Halyomorpha halys) (Stål) are a notable domestic nuisance. In addition to disruptive activity, dead individuals remain in homes, sometimes in large numbers. To better understand the effects of these remains on overwintering behavior, adult $H$. halys were subjected to several experiments to test their responses to dead conspecifics. In non-tactile tests of individuals exposed to groups of dead conspecifics, $H$. halys did not respond to 1-yr-old desiccated dead conspecifics, but avoided corpses that were freshly killed. In tactile tests of individuals exposed to groups of dead conspecifics, $H$. halys joined those corpse aggregations significantly more often than not, and preferred corpses to cotton when given a choice. In tests of exposure of overwintering individuals to fresh dead conspecifics over the course of a winter, no necrophagy or evidence of survival advantage was observed, but overall females had higher survival rates than males.
\end{abstract}

Key words: diapause, home invasion, brown marmorated stink bug, necrophagy, aggregation

The brown marmorated stink bug (Halyomorpha halys) (Stål), is a significant invasive agricultural pest (Leskey et al. 2012, Haye et al. 2015, Leskey and Nielsen 2018), and a notable domestic nuisance pest due to its habit of overwintering in human dwellings. One homeowner counted over 26,000 individuals in his home in a single year (Inkley 2012).

In addition to the fall search for harborage, $H$. halys may leave their harborage and become active in homes through winter and spring, likely in response to poor nutritional state (Funayama 2012, Skillman et al. 2018). During active periods, some become trapped and die in window frames, light fixtures, and ventilation systems. Predation by web-building spiders (Morrison et al. 2017) also leaves corpses. Others die in harborage, as overwintering temperatures affect mortality (Cira et al. 2016, Taylor et al. 2017), as does desiccation. The authors have searched many attics, crawl spaces, barns, and sheds for overwintering $H$. halys, and frequently find corpses therein, particularly in hard to reach spaces. While H. halys decomposition rates in these contexts are unknown, one author has found corpses lasting over $5 \mathrm{yr}$ in their attic.

Halyomorpha halys aggregate using antennae and a tactile response to live conspecifics (Toyama et al. 2006). Halyomorpha halys also release an alarm pheromone when disturbed. The pheromone, (E)-2-decenal (Zhang et al. 2018), is highly volatile, and will not persist in a corpse. However, the possibility of cues or survival advantage for $H$. halys from dead conspecifics exists. There is precedent for other overwintering heteropterans having responses to recently dead conspecifics. Specifically, boxelder bugs, Leptocoris trivittata (Say) (Hemiptera: Rhopalidae), have been shown to increase survivorship through conspecific necrophagy during overwintering (Brown and Norris 2004), with a majority of individuals engaging in the behavior, often soon after introduction of corpses. Halyomorpha halys have been observed engaging in cannibalism in lab-reared colonies (Medal et al. 2012), but this was on freshly molted individuals.

This article collects several exploratory studies investigating the responses of overwintering $H$. halys to dead conspecifics, in order to identify the potential importance of their many corpses. It includes tests of tactile and non-tactile responses to $H$. halys corpses, as well as overwintering survival in the presence of fresh dead conspecifics.

\section{Methods}

All experiments were conducted in a basement frequently occupied by overwintering $H$. halys in a residence in Blacksburg, VA. The space was monitored and kept at $10^{\circ} \mathrm{C}$, with two rooms kept in complete darkness. Live test subjects were collected in western and southwestern Virginia during fall overwintering seasons from the sides of buildings, or in winter from settled aggregations in homes and barns. These insects were allowed at least $48 \mathrm{~h}$ to resettle before 
use in any experiments. No individuals were reused. Year-old dead $H$. halys were unused experimental subject stock collected the previous year. All statistical analyses were performed using JMP Pro 13 (SAS Institute 2016).

\section{Non-tactile Responses to Dead Aggregations}

To test responses in the absence of visual or tactile cues, individual $H$. halys were allowed to settle in choice arenas representing a suitable overwintering habitat (Lee et al. 2014) with darkened refuges on either end, each holding screened-off portions either empty or containing living, dead, or year-old dead conspecifics.

Choice arenas were built with laser cut 3.175-mm hardboard and $1.5785-\mathrm{mm}$ acrylic. All elements were designed to interlock (Fig. 1). The overall dimensions of each arena were $240 \times 100 \times 40 \mathrm{~mm}$. Each side held removable treatment boxes sized $100 \times 55 \times 35 \mathrm{~mm}$. Treatment boxes had one screened-off open end facing the center of the apparatus. Gates were inserted $20 \mathrm{~mm}$ from each treatment box, creating a refuge space. Gates had $40 \times 6 \mathrm{~mm}$ holes to allow entry to the refuge. A small acrylic window was inserted over each refuge. A larger piece of hardboard was placed over the treatment box and refuge window to block light, which could be removed to check subject choices without allowing subjects to escape. An acrylic window was placed over the center area to permit light exposure and encourage the individuals to enter refuges, while preventing escape. Filter paper linings were placed on arena floors. Light was provided by two GE F40PL/AQ/Eco T12 fluorescent bulbs (Boston, MA) suspended $150 \mathrm{~mm}$ above the arenas. Between trials, windows were washed with soapy water, screens were wiped, arenas were left open for $24 \mathrm{~h}$ to air out, and filter paper linings were replaced. Potential off-gassing from the hardboard glue was considered negligible for the short duration of the experiment.

Treatment boxes contained either 30 living adult $H$. halys (15 male and 15 female) that had been given at least $48 \mathrm{~h}$ to re-settle in the refuge, 30 dead and partially decomposed overwintering $H$. halys from the previous year (15 male and 15 female), 30 dead adult $H$. halys ( 15 male and 15 female) killed in an oven at $65^{\circ} \mathrm{C}$ for $20 \mathrm{~min}$, or no $H$. halys. Treatment boxes were reused to reduce the total number of corpses required.

Each treatment had 30 replicates, using individual live $H$. halys, half with males and half females. Arenas were assembled with filter paper linings, with an empty treatment box on one side and a box containing insects on the other. Arenas were placed under lighting at $10^{\circ} \mathrm{C}$. Test subjects were taken from the overwintering shelter boxes, placed into lidded $25 \mathrm{~mm}$ Petri dishes, and chilled in a refrigerator for $30 \mathrm{~min}$ to allow consistent placement in dishes. Dishes were then put in the centers of arenas, dish lids were removed, and windows were replaced. Locations of $H$. halys were recorded after $5 \mathrm{~h}$. Data were analyzed using chi-squared tests with an expected value of $50 \%$.

\section{Tactile Responses to Dead Aggregations}

To test the tactile response to dead aggregations of conspecifics for shelter seeking behavior, individual $H$. halys were released into dishes containing piles of $H$. halys corpses and/or cotton, and allowed to settle.

Tests were conducted in clean 150-mm plastic Petri dishes (Fig. 2). Three treatments were tested: 10 dead H. halys, dental cotton, or both. In dead conspecific trials, 10 corpses from the previous year's unused stock were placed in each dish, lids were replaced, and dishes were then tilted so that all corpses fell to one side. In corpse and dental cotton trials, cotton was added to the opposite side of the dish.

For each treatment, 30 replicates were performed with individual overwintering $H$. halys, half male and half female. Subjects were taken from shelter boxes, and chilled in a refrigerator for $30 \mathrm{~min}$ to allow consistent placement in dishes. Live individuals were placed in the center of each dish. Lids were replaced and dishes stored in darkness at $10^{\circ} \mathrm{C}$ for $24 \mathrm{~h}$. At the end of this period, we recorded whether the live individual was in contact with the cotton, the corpses, or neither.

Although the area covered by corpses was small, live subjects could touch the aggregations while climbing on the lid of the container above as well as beside the piles. The adjacent area used for random distribution was conservatively estimated at 1:4. Therefore, distributions were analyzed in a chi-squared test that binomial proportions differed from a $20 \%$ probability of being in each corpse or cotton zone using the standard normal approximation.

\section{Winter Survival in the Presence of Dead Conspecifics}

This test of the effect of the presence of dead conspecifics on winter survival rates of $H$. halys in shelters closely follows the methodology of an experiment on L. trivittata (Brown and Norris 2004), in which

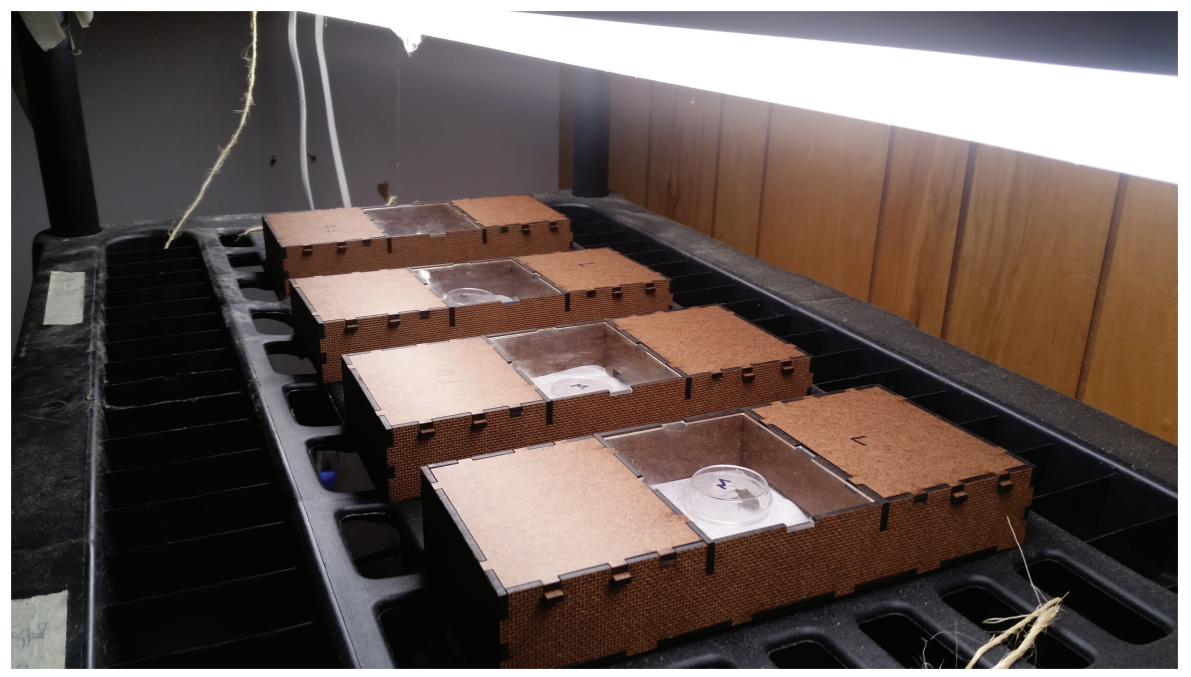

Fig. 1. Arenas for testing $H$. halys non-tactile nonvisual response to settled living and dead conspecifics. 
live individuals were provided dead conspecifics and water, and monitored throughout winter.

Plastic 6-cm-diameter Petri dishes were arranged on disposable aluminum cookie trays, 18 dishes per tray. Between observations, trays were stacked and placed in a large plastic container in darkness at $10^{\circ} \mathrm{C}$. Dishes were treated with single corpses, dental cotton with distilled water, both, or neither. Halyomorpha halys corpses provided were killed in a freezer at $-25^{\circ} \mathrm{C}$ for at least $48 \mathrm{~h}$, and stored in that freezer.

In December 2015, overwintering $H$. halys were selected for participation. Each treatment was applied to 36 individuals, half male and half female. Every $3 \mathrm{~d}$, subjects were checked for mortality. If no movement occurred, subjects were gently prodded with tweezers for a movement response to indicate life. Fresh distilled water was applied to dry dental cotton, and corpses showing signs of fungal infection were removed. Cotton showing signs of mold was replaced. Mold was wiped from dishes when observed. Every 3 wk, new corpses were provided. Mortality was recorded until May 2016. A chi-squared test of spring survival rates was used to compare treatments and interaction effects, as well as to test the survival effects of sex across all treatments.

\section{Results}

\section{Non-tactile Responses to Dead Aggregations}

In the choice tests of non-tactile responses to aggregations, no statistically significant response was found for well-settled living aggregations, nor for partially decomposed dead from previous years (Table 1). However, the settling individuals exhibited an aversion to recently killed groups $\left(\chi^{2}=4.9370, \mathrm{df}=1, P=0.0263\right)$.

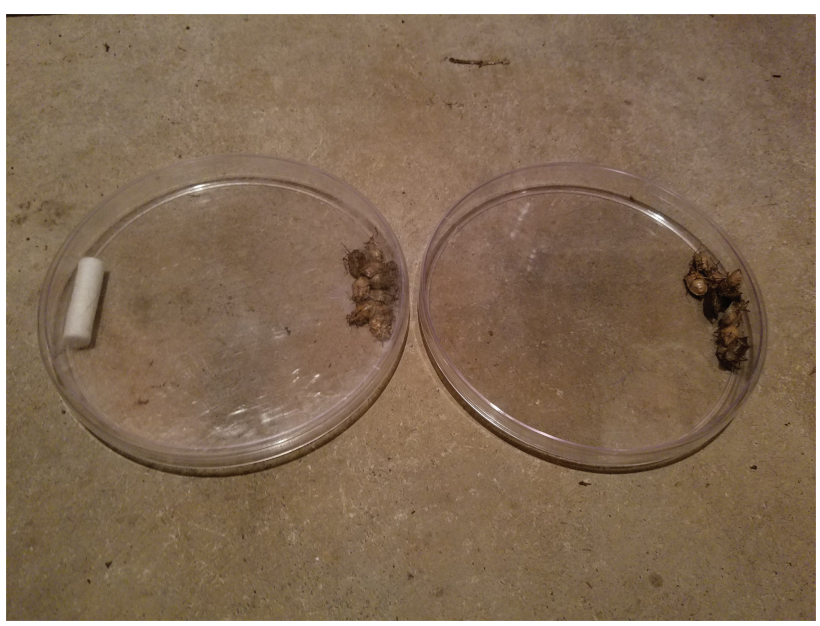

Fig. 2. Petri dishes to test single $H$. halys with dead aggregations.

\section{Tactile Responses to Dead Aggregations}

Significant responses of $H$. halys were identified with dead conspecific piles alone $\left(\chi^{2}=30.6495, \mathrm{df}=1, P<0.0001\right)$, as well as with the cotton alone $\left(\chi^{2}=13.3886, \mathrm{df}=1, P=0.0003\right.$ ) (Table 2$)$. In the trial with both, subjects showed a preference for dead conspecifics $\left(\chi^{2}=18.8692, \mathrm{df}=2, P<0.0001\right)$, with almost twice as many touching corpses as cotton.

\section{Winter Survival in the Presence of Dead \\ Conspecifics}

Subjects often settled next to the corpses, but at no point was necrophagy observed. Overall, mortality was low, at about $16 \%$. Most mortality occurred at the end of the trial (Fig. 3). Mold on corpses appeared to be more prevalent in treatments that involved water, but these data were not recorded. No significant difference in survival between treatments was observed at the end of the trial $\left(\chi^{2}=1.785\right.$, $\mathrm{df}=3, P=0.6182)$. No interaction effect was found between sex and treatment $\left(\chi^{2}=0.508, \mathrm{df}=3, P=0.917\right)$. Of the 144 individuals tested, females survived at a higher rate than males $\left(\chi^{2}=4.288\right.$, $\mathrm{df}=1, P=0.0384$ ).

\section{Discussion}

Results suggest that $H$. halys respond to dead conspecifics. This response depends on touch in the case of year-old corpses. Halyomorpha halys have previously been shown to enter and exit shelters during the fall (Watanabe et al. 1994), and it is possible that seeding trap shelters with old corpses could improve retention, or initiate the accumulation of shelter populations. Therefore, further investigation may be of use for research and control efforts.

Individuals recently killed by heating created a repellent effect in the non-tactile experiment. Semiochemicals may be involved, but were outside of our scope. Future research comparing the effects of kill method, corpse age, decomposition, and semiochemicals may help explain this effect.

No evidence of survival advantage for $H$. halys from dead conspecifics was found, though this is inconclusive due to the limited scope of this exploratory study. Future research could consider the influence of humidity, temperature, ventilation, and mold on winter survival in the presence of dead conspecifics. Overall female survival rates were higher than males, consistent with Taylor et al. (2017). If necrophagy occurred, it was not obvious, unlike with L. trivittatus (Brown and Norris 2004).

The removal of conspecific corpses from previous years is not indicated as a means of reducing the number of $H$. halys entering refuges. However, removing corpses each year may eliminate a signal for $H$. halys to settle after entering. Careful cleaning of living spaces may also reduce exposure to corpse dust from $H$. halys, which acts as an aeroallergen (Mertz et al. 2012).

Table 1. Non-tactile responses of $H$. halys to dead aggregations

\begin{tabular}{lccc}
\hline & \multicolumn{2}{c}{ Refuge Treatment Box Contents } \\
\cline { 2 - 4 } & A: Live H. halys vs. B: Empty & A: Recently Dead H. halys vs. B: Empty & A: Long Dead H. halys vs. B: Empty \\
\hline A:B & $12: 18$ & $9: 21$ & $16: 14$ \\
$\%$ Response to A & 40.0 & 30.0 & 53.3 \\
$\chi^{2}$ & 1.2081 & 4.9370 & 0.1334 \\
df & 1 & 1 & 1 \\
$P$ & 0.2717 & 0.0263 & 0.7149 \\
\hline
\end{tabular}


Table 2. Tactile responses of individual $H$. halys to dead conspecific aggregations

\begin{tabular}{lccc}
\hline & Ten dead H. halys only & Cotton only & Ten dead H. halys and Cotton \\
\hline Sample size & 30 & 30 & 30 \\
Touching corpses & $20^{*}$ & - & $15^{*}$ \\
Touching cotton & - & $15^{*}$ & $8^{*}$ \\
Touching nothing & 10 & 15 & 7 \\
\hline
\end{tabular}

* $P \leq 0.05$ in a chi-squared test between observed and expected numbers based on the assumption of random distribution.

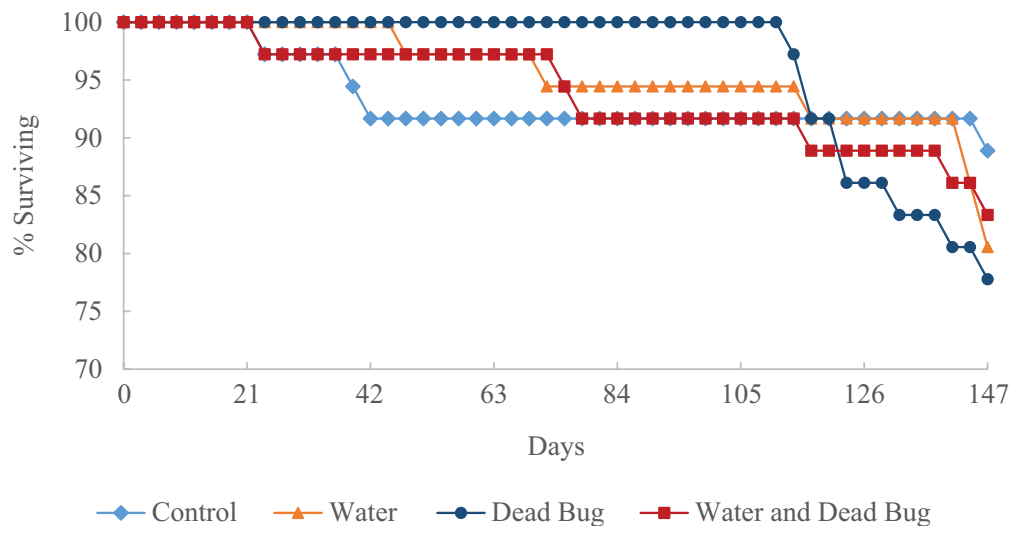

Fig. 3. Survivorship of $H$. halys through diapause, December to May.

\section{Acknowledgments}

Apparatus construction was made possible by the Virginia Tech MyersLawson School of Construction. Insect collection assistance was provided by the Virginia Tech VIPR Lab. This research assistance was provided in part by the Virginia Tech BioBuild program, and by USDA-NIFA SCRI awards 2011-51181-30937 and 2016-51181-25409.

\section{References Cited}

Brown, M. W., and M. E. Norris. 2004. Survivorship advantage of conspecific necrophagy in overwintering boxelder bugs (Heteroptera: Rhopalidae). Ann. Entomol. Soc. Am. 97: 500-503.

Cira, T. M., R. C. Venette, J. Aigner, T. Kuhar, D. E. Mullins, S. E. Gabbert, and W. D. Hutchison. 2016. Cold tolerance of Halyomorpha halys (Hemiptera: Pentatomidae) across geographic and temporal scales. Environ. Entomol. 45: 484-491.

Funayama, K. 2012. Nutritional states of post-overwintering adults of the brown-marmorated stink bug, Halyomorpha halys (Stål) (Heteroptera: Pentatomidae). Japanese J. Appl. Entomol. Zool. 56: 12-15.

Haye, T., T. Gariepy, K. Hoelmer, J-P. Rossi, J-C. Streito, X. Tassus, and N. Desneux. 2015. Range expansion of the invasive brown marmorated stink bug, Halyomorpha halys: an increasing threat to field, fruit and vegetable crops worldwide. J. Pest Sci. 88: 665-673.

Inkley, D. B. 2012. Characteristics of home invasion by the brown marmorated stink bug (Hemiptera: Pentatomidae). J. Entomol. Sci. 47: 125-130.

Lee, D-H., J. P. Cullum, J. L. Anderson, J. D. Daugherty, L. M. Beckett, and T. C. Leskey. 2014. Characterization of overwintering sites of the invasive brown marmorated stink bug in natural landscapes using human surveyors and detector canines. PLoS One. 9: e91575. doi:10.1371/journal.pone.0091575

Leskey, T. C., and A. L. Nielsen. 2018. Impact of the invasive brown marmorated stink bug in North America and Europe: history, biology, ecology, and management. Annu. Rev. Entomol. 63: 599-618.
Leskey, T. C., G. P. Dively, C. R. R. Hooks, M. J. Raupp, P. M. Shrewsbury, G. Krawczyk, P. W. Shearer, J. Whalen, C. Koplinka, E. Myers, et al. 2012. Pest status of the brown marmorated stink bug, Halyomorpha halys in the USA. Outlooks Pest Manag. 23: 218-226.

Medal, J., T. Smith, A. Fox, A. Santa Cruz, A. Poplin, and A. Hodges. 2012. Rearing the brown marmorated stink bug Halyomorpha halys (Heteroptera: Pentatomidae). Florida Entomol. 95: 800-802.

Mertz, T. L., S. B. Jacobs, T. J. Craig, and F. T. Ishmael. 2012. The brown marmorated stinkbug as a new aeroallergen. J. Allergy Clin. Immunol. 130: 999-1001.e1.

Morrison, W. R., A. N. Bryant, B. Poling, N. F. Quinn, and T. C. Leskey. 2017. Predation of Halyomorpha halys (Hemiptera: Pentatomidae) from webbuilding spiders associated with anthropogenic dwellings. J. Insect Behav. 30: 70-85.

SAS Institute. 2016. JMP Pro version 13.0.0. SAS Institute, Cary, NC.

Skillman, V. P., N. G. Wiman, and J. C. Lee. 2018. Nutrient declines in overwintering Halyomorpha halys populations. Entomol. Exp. Appl. 166: 778-789.

Taylor, C. M., P. L. Coffey, K. A. Hamby, and G. P. Dively. 2017. Laboratory rearing of Halyomorpha halys: methods to optimize survival and fitness of adults during and after diapause. J. Pest Sci. 90: 1069-1077.

Toyama, M., F. Ihara, and K. Yaginuma. 2006. Formation of aggregations in adults of the brown marmorated stink bug, Halyomorpha halys (Stål) (Heteroptera: Pentatomidae). Appl. Entomol. Zool. 41: 309-315.

Watanabe, M., R. Arakawa, Y. Shinagawa, and T. Okazawa. 1994. Fluctuation in brown marmorated stinkbug's winter migrations into human dwellings. Japan Soc. Med. Entomol. Zool. Anim. Heal. 45: 25-31.

Zhong, Y., R. Tang, J. Zhang, S. Yang, G. Chen, K. He, Z. Wang, and F. Zhang. 2018. Behavioral evidence and olfactory reception of a single alarm pheromone component in Halyomorpha halys. Front. Physiol. 9: 1610. doi:10.3389/fphys.2018.01610 